\title{
Immunohistochemical study of PrPSc distribution in neural and extraneural tissues of two cats with feline spongiform encephalopathy
}

\author{
Monika M Hilbe*†, Guido G Soldati ${ }^{\dagger}$, Kati K Zlinszky, Sabina S Wunderlin \\ and Felix F Ehrensperger
}

Address: Institute of Veterinary Pathology, Vetsuisse Faculty Zurich, Winterthurerstrasse 268, 8057 Zurich, Switzerland

Email: Monika M Hilbe* - hilbe@vetpath.uzh.ch; Guido G Soldati - guidosoldati@ hotmail.com; Kati K Zlinszky - zlin@vetpath.uzh.ch; Sabina S Wunderlin - wusl@bluewin.ch; Felix F Ehrensperger - f.ehrensperger@vetpath.uzh.ch

* Corresponding author †Equal contributors

Published: 31 March 2009

BMC Veterinary Research 2009, 5:II doi:10.1 I86/1746-6148-5-II

This article is available from: http://www.biomedcentral.com/l746-6/48/5/II

(c) 2009 Hilbe et al; licensee BioMed Central Ltd.

This is an Open Access article distributed under the terms of the Creative Commons Attribution License (http://creativecommons.org/licenses/by/2.0), which permits unrestricted use, distribution, and reproduction in any medium, provided the original work is properly cited.
Received: 5 September 2008

Accepted: 31 March 2009

\begin{abstract}
Background: Two domestic shorthair cats presenting with progressive hind-limb ataxia and increased aggressiveness were necropsied and a post mortem diagnosis of Feline Spongiform Encephalopathy (FSE) was made. A wide spectrum of tissue samples was collected and evaluated histologically and immunohistologically for the presence of PrPSc.

Results: Histopathological examination revealed a diffuse vacuolation of the grey matter neuropil with the following areas being most severely affected: corpus geniculatum medialis, thalamus, gyrus dentatus of the hippocampus, corpus striatum, and deep layers of the cerebral and cerebellar cortex as well as in the brain stem. In addition, a diffuse glial reaction involving astrocytes and microglia and intraneuronal vacuolation in a few neurons in the brain stem was present.

Heavy PrPSc immunostaining was detected in brain, retina, optic nerve, pars nervosa of the pituitary gland, trigeminal ganglia and small amounts in the myenteric plexus of the small intestine (duodenum, jejunum) and slightly in the medulla of the adrenal gland.

Conclusion: The PrPSc distribution within the brain was consistent with that described in other FSE-affected cats. The pattern of abnormal PrP in the retina corresponded to that found in a captive cheetah with FSE, in sheep with scrapie and was similar to nvCJD in humans.
\end{abstract}

\section{Background}

Feline spongiform encephalopathy (FSE) is a prioninduced disease affecting the cat family felidae. FSE belongs to the group of transmissible spongiform encephalopathies (TSE) occurring in humans and other animal species. The first report was from a Siamese cat [1]. To date, 89 cases of FSE have been reported in domestic cats in Great Britain, one in Northern Ireland, one in Liechten- stein (DEFRA) [2], one in Norway [3], one in Italy [4] and one in Switzerland [5]. In addition, spongiform encephalopathies have been described in other feline species including cheetahs, pumas, ocelots, tigers and lions (DEFRA) [2]. The disease is characterized by progressive onset of clinical signs including abnormal behaviour such as increased timidity or aggression, ataxia and hyperaesthesia. The main histopathological lesions are vacuola- 
tion of the neuropil in the grey matter of the brain and spinal cord (also referred as spongiosis), vacuolation of neuronal perikarya, and a diffuse astrocytic reaction $[6,7]$. Lesion profiles, transmission experiments in mice and western blotting studies have provided strong evidence that FSE is caused by the same agent, which causes bovine spongiform encephalopathy (BSE) in cattle and new variant Creutzfeldt-Jakob Disease (nvCJD) in humans. Based on these observations, the condition in cats is believed to result from ingestion of BSE contaminated food [6,8-10]. In 1998, the simultaneous occurrence of spongiform encephalopathy in a man and his cat was reported [4]. The question remains whether the disease had spread either horizontally, from a common source or even by chance. Western blot analysis of feline brain homogenates showed a type- 1 PrPres strain which was comparable to those observed in sporadic CJD [4]. In 2001, extraneural tissues of cats with FSE were investigated by immunohistochemistry (IHC); small amounts of PrPSc were detected in the spleen of 2 out of 13 cats, in Peyer's patches of 1 out of 2 cats and in the kidney of every FSE cat. However, PrPSc deposits were also found in the kidney of 1 control cat even after proteinase K digestion [11]. In 2003, a similar study was performed on tissues from a cheetah with FSE. PrPSc accumulation was detected in the kidney and, in contrast to cats, in lymph nodes and adrenal gland, whereas the spleen was negative [12]

Two cases of FSE, out of total 2810 cats necropsies during the period 1996 and 2003, were diagnosed at our Institute. In both FSE-cases, a number of neural and extraneural formalin-fixed and paraffin-embedded tissues were available for further studies. The aim of this study was to employ IHC and to compare our results with those published in the literature and with FSE negative control cats.

\section{Methods \\ Animals \\ Case 1}

A 9-year-old, neutered, male domestic shorthaired cat from the Principality of Liechtenstein was presented in August 1996 with a 3-week history of poor appetite, increasing aggressiveness and locomotor dysfunction with hind-limb ataxia. The cat was euthanized end of 1996. No information was available about feeding habit.

\section{Case 2}

A 7-year-old, neutered, female domestic shorthaired cat originating from the canton Schwyz in Switzerland was euthanized in May 2003 because of therapy resistant progressive ataxia in all four limbs. The cat was fed throughout life with canned food.

Six cats euthanized between 2006 and 2007 for multiple reasons, ranging from neoplasia to car accident, but with- out CNS symptoms were used as negative controls. The age of these cats was between 9 and 13 years.

\section{Pathologic examination}

Post mortem examination was carried out on 2 FSE and 6 control cats. A wide spectrum of tissue samples (Table 1) was collected, fixed in $10 \%$ neutral buffered formalin, routinely processed, embedded in paraffin and sections were stained with haematoxylin and eosin for histopathological examination.

\section{PrP immunohistochemistry}

The PrP IHC was performed using two monoclonal antibodies (mabs: 34c9 and 6H4, Prionics Switzerland). The monoclonal antibody 34c9 recognizes the sequence LIHFG in the bovine prion protein (corresponding to position 138-142 with numbering according to human PrP; data sheet Prionics Switzerland) and the monoclonal antibody $6 \mathrm{H} 4$ identifies the sequence DYEDRYYRE in the center of the protease-resistant core of the bovine prion protein (amino acids 144-152 in the human PrP; data sheet Prionics Switzerland, [13]). 10\% formalin fixed slices of the organs prepared for paraffin-embedding were decontaminated in formic acid for 1 hour (98\%, Sigma Switzerland) and afterwards fixed once again in $10 \%$ formalin for 48 hours. Sections of paraffin embedded tissues were dried over night at $37^{\circ} \mathrm{C}$ and de-paraffinized. They were then treated with proteinase $\mathrm{K}$ (Proteinase sigma Type XXIV) during 15 minutes at room temperature (RT) and then autoclaved (Bench-top autoclav, Systec, 3850 EL, Switzerland) in citrate puffer ( $\mathrm{pH} \mathrm{6}$, Target Retrieval Solution, Dako S2031) at 1 bar and a temperature of $121^{\circ} \mathrm{C}$ during 30 minutes. The endogenous peroxidase was blocked by $\mathrm{H}_{2} \mathrm{O}_{2} 3 \%$ for 5 minutes at RT. A protein block (10 minutes at RT; Dako, X0909, Switzerland) as well as avidin/biotin block (20 minutes at RT each; Blocking Kit, Vector Laboratories Inc., Burlingame, USA) were performed afterwards. The slides were incubated with the primary antibodies over night at RT (34c9 1:1000 and 6H4 1:50) upon which the ChemMate Detection Kit that can be used with both rabbit and mouse primary antibodies was applied as described by the manufacturer (Rabbit/ Mouse HRP Detection Kit, DakoChemMate K5001 and K5003). Finally, the slides were visualized by DAB (brown coloration, Diaminobenzidine, Dako, K3464) or AEC (red coloration, Aminoethylcarbazole, Zymed Laboratories Inc., 00-2007) for 10 minutes and counterstained with hemalaun for 10 seconds.

A negative control of each section was performed using PBS (phosphate buffer solution, pH8) instead of the primary antibody. A section of the medulla oblongata from a BSE-infected cow was included to validate the procedure with every run. 
Table I: Immunohistochemical distribution of PrPSc in neural and extraneural tissues of two FSE cats and control cats

\begin{tabular}{|c|c|c|c|c|c|c|}
\hline \multirow{2}{*}{$\begin{array}{l}\text { Organ system } \\
\text { Antibodies }\end{array}$} & \multicolumn{2}{|c|}{ FSE cat no. I } & \multicolumn{2}{|c|}{ FSE cat no. 2} & \multicolumn{2}{|c|}{ Contol cats $(n=6)$} \\
\hline & $34 \mathrm{c} 9$ & $6 \mathrm{H} 4$ & $34 c 9$ & $6 \mathrm{H} 4$ & $34 c 9$ & $6 \mathrm{H} 4$ \\
\hline \multicolumn{7}{|l|}{ Brain: } \\
\hline \multicolumn{7}{|l|}{ Cerebrum: } \\
\hline Cerebral cortex & +++ & +++ & +++ & +++ & - & - \\
\hline Gyrus dentatus & +++ & +++ & +++ & +++ & - & - \\
\hline \multicolumn{7}{|l|}{ Cerebellum: } \\
\hline Molecular layer & + & + & + & + & - & - \\
\hline Purkinje cell layer & - & - & - & - & - & - \\
\hline Granular cell layer & +++ & +++ & +++ & +++ & - & - \\
\hline Brain stem & +++ & +++ & +++ & +++ & - & - \\
\hline Nervus opticus & ++ & ++ & ++ & ++ & - & - \\
\hline \multicolumn{7}{|l|}{ Retina: } \\
\hline Rod and cone layer & + & + & + & + & - & - \\
\hline Outer nuclear layer & - & - & - & - & - & - \\
\hline Outer plexiform layer & + & + & + & + & - & - \\
\hline Inner nuclear layer & - & - & - & - & - & - \\
\hline Inner plexiform layer & +++ & +++ & +++ & +++ & - & - \\
\hline Ganglion cell layer & + & + & + & + & - & - \\
\hline \multicolumn{7}{|l|}{ Pituitary gland: } \\
\hline Pars distalis & - & - & - & - & - & - \\
\hline Pars intermedia & - & - & - & - & - & - \\
\hline Neurohypophysis & +++ & +++ & +++ & +++ & - & - \\
\hline Trigeminal ganglion & n.d. & n.d. & +++ & +++ & - & - \\
\hline Myenteric plexus (duodenum, jejunum, colon) & + & + & + & + & - & - \\
\hline \multicolumn{7}{|l|}{ Lymphoid system: } \\
\hline Spleen & - & - & - & - & - & - \\
\hline GALT & n.d. & n.d. & - & - & - & - \\
\hline Bone marrow & - & - & - & - & - & - \\
\hline Nictitating membrane follicles & n.d. & n.d. & - & - & - & - \\
\hline Heart & - & - & - & - & - & - \\
\hline Lung & - & - & - & - & - & - \\
\hline Thyroid gland & - & - & - & - & - & - \\
\hline Parathyroid gland & - & - & - & - & - & - \\
\hline Salivary gland & n.d. & n.d. & - & - & - & - \\
\hline Nasal mucosa & n.d. & n.d. & - & - & - & - \\
\hline Liver & - & - & - & - & - & - \\
\hline Pancreas & - & - & - & - & - & - \\
\hline \multicolumn{7}{|l|}{ Kidney: } \\
\hline Glomerular capillary tuft & $+^{\circ}$ & - & - & - & $++3 / 6^{\circ}$ & $+2 / 6^{\circ}$ \\
\hline Tubules & - & - & - & - & - & - \\
\hline
\end{tabular}


Table I: Immunohistochemical distribution of PrPSc in neural and extraneural tissues of two FSE cats and control cats (Continued)

\begin{tabular}{|c|c|c|c|c|c|c|c|}
\hline \multicolumn{8}{|l|}{ Adrenal gland: } \\
\hline & Zona glomerulosa & - & - & n.d. & n.d. & - & - \\
\hline & Zona fasciculate & - & - & n.d. & n.d. & - & - \\
\hline & Zona reticularis & - & - & n.d. & n.d. & - & - \\
\hline & Medulla & + & + & n.d. & n.d. & - & - \\
\hline & Muscle (striated) & n.d. & n.d. & - & - & - & - \\
\hline
\end{tabular}

$+=$ weak $;++=$ moderate $;+++=$ strong immunostaining; n.d. $=$ not done ${ }^{\circ}=$ considered as unspecific

\section{Results}

\section{Pathological and histological findings}

Cat 1 had excessive body fat accumulation and a moderate hypertrophic cardiomyopathy. No macroscopic lesions were observed in the central nervous system (CNS). Cat 2 had no significant gross changes.

Histopathological lesions were identical in both cases and were confined to the CNS. They consisted principally of spongiform changes observed as a moderate to severe diffuse vacuolation of the grey matter neuropil (Figure 1) with the following areas being most severely affected: corpus geniculatum medialis, thalamus, gyrus dentatus of the hippocampus, corpus striatum, and deep layers of the cerebral and cerebellar cortex as well as in the brain stem. In addition, a diffuse glial reaction involving astrocytes and microglia and intracytoplasmic vacuolation in a few neurons in the caudal brain stem was present.

\section{Immunohistochemical findings}

\section{Central Nervous System}

Throughout the grey matter within the cerebral cortex and along the whole brainstem intracytoplasmic neuronal multigranular deposits were seen both in the perikarya

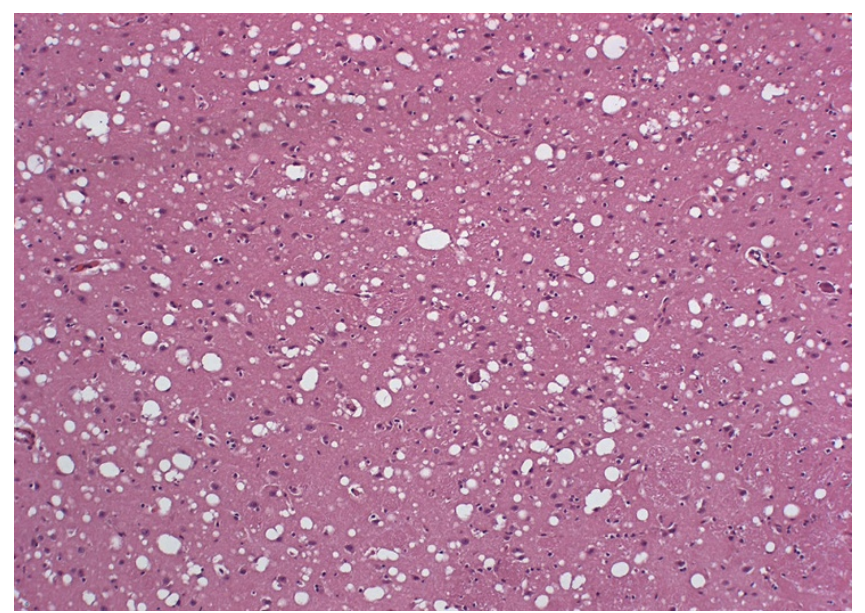

Figure I

Severe, diffuse vacuolation of the neuropil in the cerebral cortex in FSE cat no. I. Haematoxylin and eosin stain, I0x objective. and the axons. Often the intraaxonal granules were arranged in a linear way. The $\mathrm{PrPSc}^{\mathrm{imm}} \mathrm{mon}$ ostaining in the grey matter and in the brain stem (Figure 2) was more prominent in the areas with spongiform lesions. In the granular cell layer of the cerebellum, a strong fine punctuated to granular intracytoplasmic immunolabelling was evident. A weak granular staining was also detected intracytoplasmically in the molecular cell layer and in the perikarya of Purkinje cells. No immunodeposits were found in the white matter of the cerebellum.

The intensity and distribution of $\operatorname{PrPSc}^{\mathrm{s}}$ was very similar in both FSE-cases and no significant differences were observed between the 2 applied antibodies. PrPSc staining in the brain of the 6 control cats was negative (Table 1 ).

\section{Eye}

A marked PrPSc accumulation was detected in the inner and a slight deposit in the outer plexiform layer of the retina. Small amounts of granular deposits were also present within the rod and cone layer and ganglion cell layer as well as in the axons of the optic nerve. No positive stain-

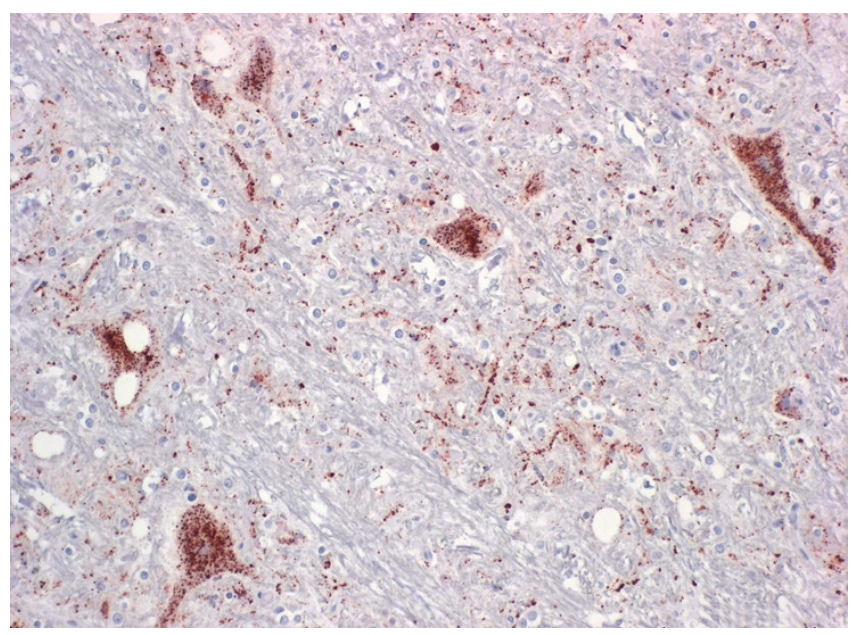

\section{Figure 2}

Detection of prion protein in the brain stem in FSE cat no. 2. Note the multigranular intracytoplasmic staining in the neuronal perikaryon and linear axonal positive staining (dark brown color) in the neuropil. Immunohistochemistry, mab 34c9, 20x objective. 


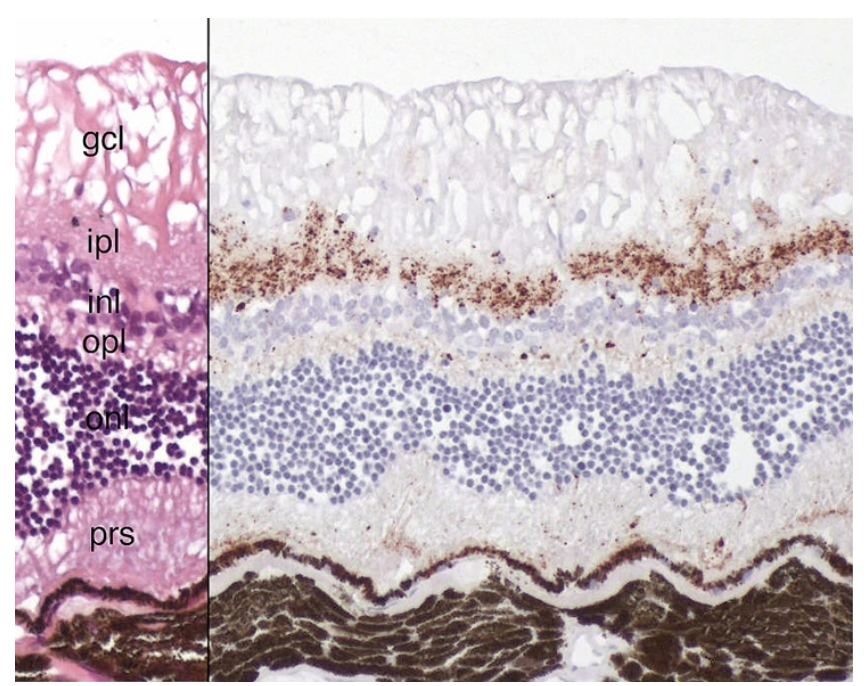

Figure 3

Detection of prion protein in the retina of FSE cat no. I. Left side: Haematoxylin and eosin stain. $\mathrm{Gcl}=$ ganglion cell layer, ipl = inner plexiform layer, inl = inner nuclear layer, opl = outer plexifom layer, onl = outer nuclear layer, prs = photoreceptors. Right side: Marked to slight granular PrPSc accumulation (dark brown color) in inner and outer plexiform layers, small amount of granular deposits within the rod and cone layer and ganglion cell layer are visible. No positive staining can be discerned in the inner and outer nuclear layers or in the nerve fibre layer. Immunohistochemistry, mab $34 c 9,40 \times$ objective.

ing was seen in inner and outer nuclear layers or in the nerve fibre layer (Figure 3). This finding was identical in the eyes of both cats with FSE. No PrPsc staining was found in the eyes of the 6 control cats.

\section{Pituitary gland and trigeminal ganglion}

Large amounts of disease specific PrPSc was also found within axonal processes of the pars nervosa of the pituitary gland (Figure 4) and within perikarya of the trigeminal ganglia (Figure 5) of FSE cat no. 2 (Table 1). No trigeminal ganglion was available from the second cat with FSE. The pituitary gland as well as the trigeminal ganglia of the control cats stained negative for $\mathrm{PrPSc}^{\mathrm{Sc}}$

\section{Intestine}

PrPSc had accumulated in the myenteric plexus of the enteric nervous system in both FSE affected cats, where a fine granular staining was observed within the cytoplasm of neurons in the duodenum and jejunum (Figure 6). Immunohistochemical staining for PrPSc in the control cats was negative in the plexus myentericus of the small and large intestine.

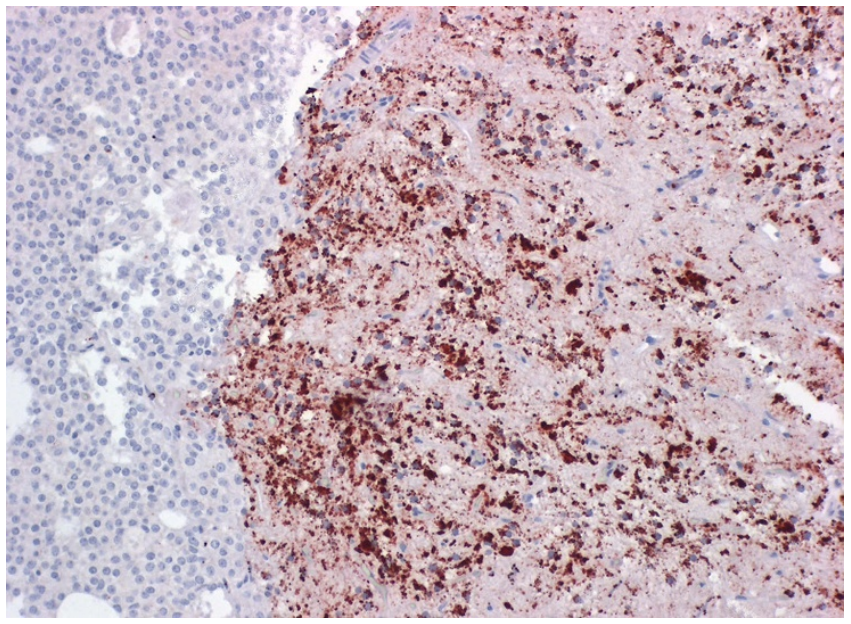

Figure 4

Immunohistochemical detection of prion protein in the neurohypophysis of FSE cat no. 2. The staining is marked and mostly granular (dark brown color). Immunohistochemistry, mab $6 \mathrm{H} 4,20 \times$ objective.

\section{Lymphoid system and Bone Marrow}

Immunostaining with mabs 34c9 and 6H4 was negative in spleen, GALT (only examined in FSE cat no. 2; Table 1), bone marrow and nictitating membrane follicles (only examined in FSE cat no. 2) in FSE cats and all controls.

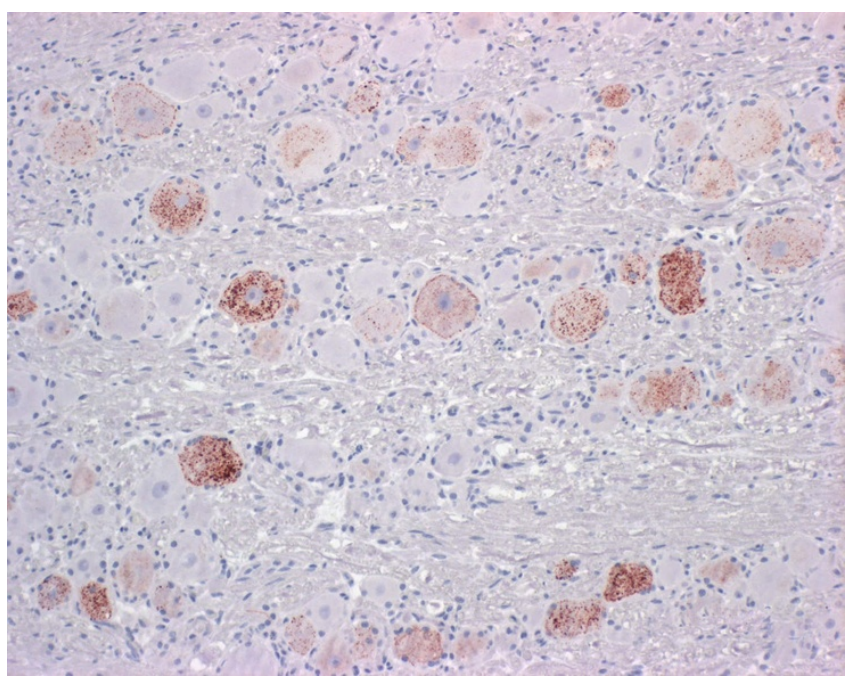

Figure 5

Immunohistochemical detection of prion protein in the trigeminal ganglion in FSE cat no. 2. Moderate intracytoplasmic granular staining (dark brown color) is visible. Immunohistochemistry, mab $6 \mathrm{H} 4,20 \times$ objective. 


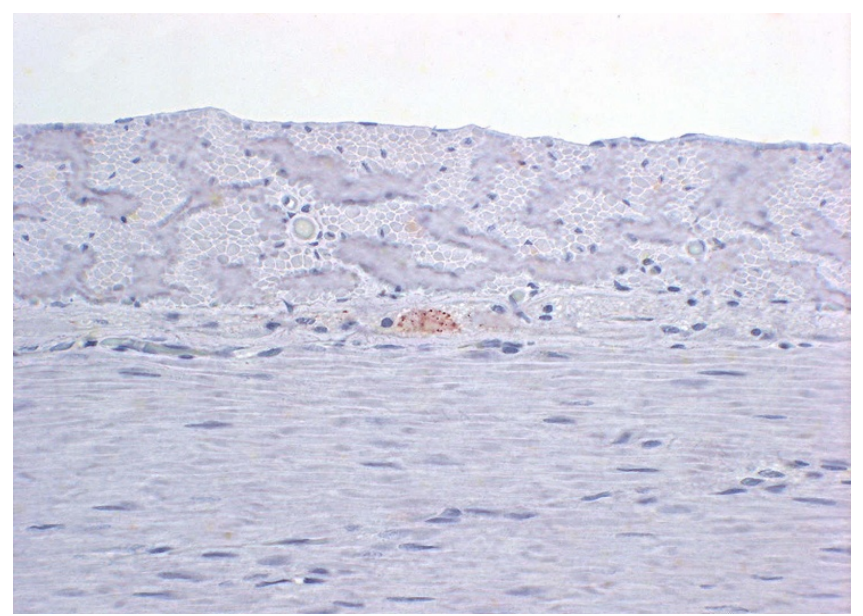

Figure 6

Immunohistochemical detection of prion proteins in the plexus myentericus (dark brown color) in the small intestine of FSE cat no. I. Immunohistochemistry, mab 34c9, 100× objective.

\section{Kidneys}

Few glomerular capillary tufts stained weakly positive in the kidney of FSE cat no. 1 with mab 34c9. In the control cats, glomerular capillary tufts (3/6 with 34c9, 2/6 with $6 \mathrm{H} 4)$ stained with different intensity with the 2 monoclonal antibodies (Figure 7; Table 1). PBS controls were always negative (Figure 8).

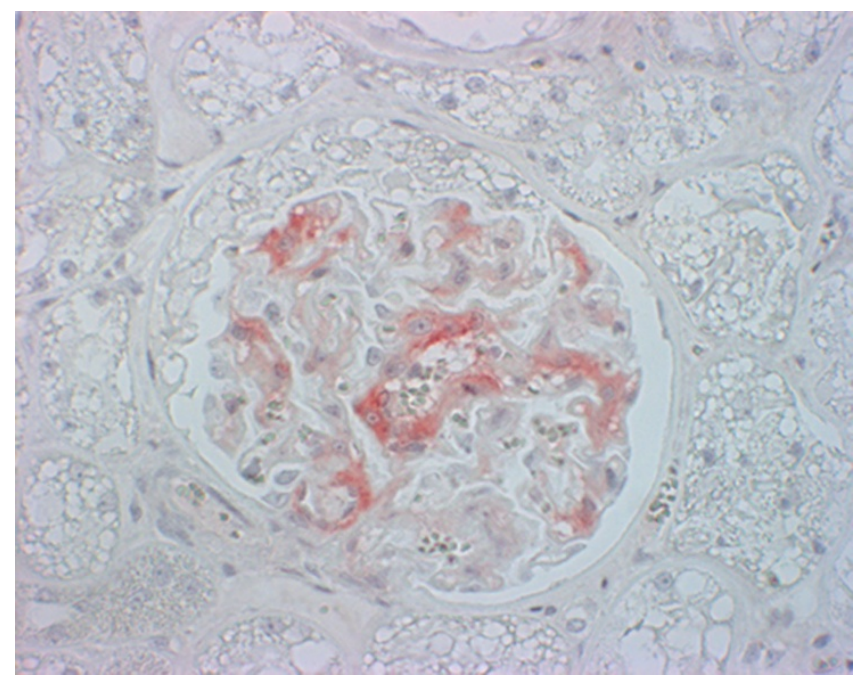

Figure 7

Immunohistochemical staining of prion protein (red color) in the glomerular capillary tuft in a control cat. Immunohistochemistry, mab 34c9, 40× objective.

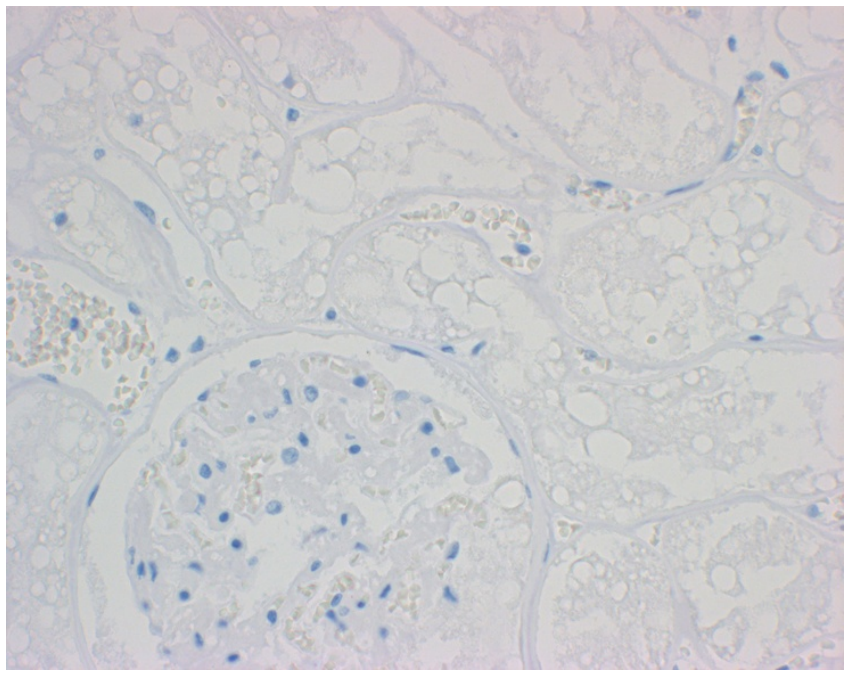

Figure 8

PBS control of the kidney of FSE cat no. 2. Note that glomeruli and tubules show no positive labelling.

Immunohistochemistry, $40 \times$ objective

\section{Adrenal glands}

The adrenal gland was available only in FSE cat no. 1 and some medullary cells were positive with the monoclonal antibodies 34c9 and 6H4. A slight granular and intracytoplasmic staining pattern was visible. The adrenal glands of all control cats were negative with the 2 antibodies applied.

\section{Other tissues}

The heart, thyroid, parathyroid and salivary glands, the nasal mucosa, liver, pancreas and striated muscle were negative in all cats.

\section{Discussion}

Histopathologic lesions in the 2 FSE cases consisted of a diffuse vacuolation of the grey matter neuropil, vacuolation of neuronal perikarya and gliosis. Heavy PrPsc immunostaining was detected in brain (grey matter neuropil of cerebrum, cerebellum and brain stem), retina (inner and outer plexiform layer, rod and cone layer and ganglion cell layer), optic nerve, pars nervosa of the pituitary gland, adrenal medulla, trigeminal ganglia and myenteric plexus of the small intestine. In addition, a weak labelling was observed the kidney (glomerular capillary tufts) in FSE cat no. 1, which was interpreted as non-specific, as similar reaction patterns were seen in control animals. Nictitating membrane, nasal mucosa, salivary gland, heart, pancreas, thyroid gland, parathyroid gland, striated muscle and bone marrow were negative. Two monoclonal antibodies as described above were used to label different PrPSc regions for more sensitivity in recognizing the prion protein distibution, intensity and type of depositions. 
Both the histological lesions and the PrPSc distribution within the brain seen in the 2 FSE cases presented here is similar to that described in other FSE-affected cats $[1,3$ $6,14,15]$, a puma [16] and three cheetahs $[12,17,18]$. The pattern of abnormal PrPSc in the retina corresponds to that found in a captive cheetah with FSE [12] and in sheep with scrapie [19-22]. In nvCJD in humans the PrPSc staining is restricted to the inner and outer plexiform layer but the photoreceptor cells or other neuronal cell bodies were negative [23].

Some authors investigated the distribution of $\mathrm{PrPSc}$ in extraneuronal tissues in cats with FSE and found small amounts in 2 of 13 spleens, in 1 of 2 Peyer's patches and in the myenteric plexus of all 4 examined cats. They did not include the eye, pituitary gland, trigeminal ganglion and adrenals in their study [11].

Numerous follicles in spleen, GALT and nictitating membrane and the bone marrow of our cats were negative for PrPSc with both monoclonal antibodies. The authors of the study mentioned above stated that the restricted distribution of disease-specific PrPsc in the lymphoid tissue of their cats was strikingly different from that observed in scrapie in sheep and resembles, in part, the distribution of PrPSc in cattle experimentally infected with BSE by the oral route [11].

The demonstration of $\mathrm{PrPSc}^{\mathrm{S}}$ in the enteric nervous system is in agreement with other reports of FSE in cats [11] and of scrapie in sheep [19]. PrPSc deposits could however not be detected in the enteric nervous system of the cheetah affected with FSE [12].

Positive PrPSc staining in the glomeruli of cats with FSE and in their control cats was found in one study and the authors could not exclude a non-specific staining [11]. Likewise, a small percentage of glomeruli within the cortical and juxtamedullary regions in the kidney of a FSE positive cheetah stained intensely for $\mathrm{PrPSc}^{\mathrm{s}}$ with four different monoclonal antibodies. The pathological significance of this finding was regarded as not clear [12]. In our study, both monoclonal antibodies (34c9 and 6H4) showed randomly distributed some positive reaction in the glomerular capillary tufts. As one FSE case and control cats were positive, this finding was interpreted to be non-specific (Table 1). Nevertheless, some studies postulate a possible excretion of prions through urine (prionuria) and that this may play a role in the horizontal transmission of TSEs [24,25]. In Syrian hamsters experimentally infected by intracranial injection of scrapie brain homogenate the authors found TSE infectivity in the urine of hamsters without signs of inflammation in the kidney and in the bladder [25]. The FSE cats described here also did not show any inflammatory processes in the kidney. In kid- neys from ARQ/ARQ scrapie-affected sheep PrPsc can be found in the medullary and the cortical region intraepithelially [24]. In contrast in FSE cats the deposition was not only found in tubular structures but also in glomerula.

In kidneys of experimentally and naturally scrapieaffected sheep, disease-associated PrP was shown to accumulate in the interstitium of renal papillae without inflammatory reaction and this contrasts with the unspecific glomerular accumulation of PrPsc found in our cats and the cats and the cheetah previously published $[11,12,26]$.

In cattle orally infected with BSE immunostaining in the follicles of the distal ileum was observed only after the onset of clinical disease at 36, 38 and 40 months after exposure [27]. Neurons in the enteric nervous system were positive in only one animal from each of the groups killed 38 and 40 months after exposure, but even then the staining was sparse and confined to the myenteric plexus. In contrast none of the follicles in the distal ileum showed evidence of immunostaining for $\mathrm{PrPSc}^{\mathrm{Sc}}$ and only a few animals showed sparse staining in the myenteric plexus in naturally affected cattle with BSE. The mesenteric lymph nodes were negative 6 months after exposure in the experimental animals. Some authors concluded that the restricted distribution of the BSE agent in the lymphoreticular system of cattle contrasts with the distribution of the scrapie agent in sheep which, in most cases, spreads rapidly after the initial early involvement of the system [27]. The restricted distribution of BSE appears to be also true for FSE. Mice inoculated intraperitoneally or intracerebrally with brain material from cats with FSE had progressive neurological signs similar to those seen in mice affected with scrapie or BSE. Moreover some authors postulate, that the distribution of vacuolar degeneration was identical to that seen in mice terminally infected with primary sources of BSE and the lesion profile in mice inoculated with FSE resembles that observed in BSE, rather than scrapie. It was postulated, therefore, that BSE and FSE probably arose from a common source [10]. The source of infection at least in one cat presented here could have been canned food contaminated with nervous tissue of BSE infected cattle before the ban.

\section{Conclusion}

In conclusion, the two FSE cases described here had essentially the same histological lesions and $\mathrm{PrPSc}^{\mathrm{S}}$ distribution in the brain and the peripheral tissues as reported in earlier FSE cases. In addition we were able to demonstrate PrPSc accumulation in the retina, the neurohypophysis, trigeminal ganglion and in the adrenal medulla, but not in lymphatic tissues nor in the bone marrow. The kidneys showed random immunohistochemical staining in the 
mesangial glomerular tufts. This was seen in the kidneys of one FSE as well as in the control cats. Even though in experimentally infected Syrian hamsters and in scrapie infected sheep a possible prionuria and infectivity of urine is postulated, our findings confirm previously reported observations in the kidney of FSE cases, showing that immunohistochemical labelling of glomerular structures has to be regarded as unspecific. In summary, the distribution of PrPSc in FSE is similar to BSE but different from classical scrapie. In analogy, horizontal PrPsc transmission in FSE appears to be unlikely.

\section{Authors' contributions}

$\mathrm{MH}, \mathrm{GS}$ and FE designed the study, contributed in the acquisition of the material and interpretation of the data, commented on the draft and read the manuscript. KZ and SW were responsible for the immmunhistological work.

\section{References}

I. Wyatt JM, Pearson GR, Smerdon T, Gruffydd-Jones TJ, Wells GAH: Spongiform encephalopathy in a cat. Veterinary Record 1990, I 9:513.

2. $\quad$ DEFRA $=$ Department for Environment Food and Rural Affairs (ex MAFF = Ministry of Agriculture, Fisheries and Food): UK Statistic on incidence of BSE and related diseases. [http://
[ www.defra.gov.uk/vla/science/sci tse stats exotic.htm].

3. Bratberg B, Ueland K, Wells GAH: Feline spongiform encephalopathy in a cat in Norway. Veterinary Record 1995, I 36:444.

4. Zanusso G, Nardelli E, Rosati A, Fabrizi G, Ferrari S, Carteri A, De Simone F, Rizzuto N, Monaco S: Simultaneous occurrence of spongiform encephalopathy in a man and his cat in Italy. Lancet 1998, 352:1116-1117.

5. Demierre S, Botteron C, Cizinauskas S, Doherr MG, Fatzer R, Jaggy A: Feline spongiforme Enzephalopathie: Erster klinischer Fall in der Schweiz. Schweiz Arch Tierheilk 2002, I 44:550-557.

6. Wyatt JM, Pearson GR, Smerdon TN, Gruffydd-Jones TJ, Wells GAH, Wilesmith JW: Naturally occurring scrapie-like spongiform encephalopathy in five domestic cats. Vet $\operatorname{Rec} 1991$, I 29( I I):233-236.

7. Wyatt JM, Pearson GR: Feline Spongiform Encephalopathy. Feline Practice 1993, 2 I:7-9.

8. Bruce ME, Will RG, Ironside JW, McConnell I, Drummond D, Suttie A, McCardle L, Chree A, Hope J, Birkett C, Cousens S, Fraser H, Bostock CJ: Transmission to mice indicate that new variant CJD is caused by the BSE agent. Nature I997, 389:498-50I.

9. Collinge J, Sidle KCL, Mead J, Ironside J, Hill AF: Molecular analysis of prion protein variation and the aetiology of new variant CJD. Nature 1996, 383:685-690.

10. Fraser H, Pearson GR, McConnel I, Bruce ME, Wyatt JM, GruffyddJones TJ: Transmission of feline spongiform encephalopathy to mice. Vet Rec 1994, I 34( I 7):449.

II. Ryder SJ, Wells GAH, Bradshaw M, Pearson GR: Inconsistent detection of PrP in extraneural tissues of cats with feline spongiform encephalopathy. Veterinary Record 200I, 7:437-440.

12. Lezmi S, Bencsik A, Monks E, Petit T, Baron T: First case of feline spongiform encephalopathy in a captive cheetah born in France: PrPSc analysis in various tissues revealed unexpected targeting of kidney and adrenal gland. Histochem Cell Biol 2003, I I 9:4 I5-422.

13. Meyer RK, Oesch B, Fatzer R, Zubriggen A, Vandevelde M: Detection of bovine spongiform encephalopathy-specific PrPSc by treatment with heat and guanidine thiocyanate. J Virol 1999, 73(I I):9386-9392.

14. Leggett MM, Dukes J, Pirie HM: A spongiform encephalopathy in a cat. Veterinary Record 1990, I5:586-588.

15. Pearson GR, Wyatt JM, Gruffydd-Jones TJ, Hope J, Chong A, Higgins RJ, Scott AC, Wells GAH: Feline spongiform encephalopathy: fibril and PrP studies. Veterinary Record 1992, 3:307-3 I0.
16. Willoughby K, Kelly DF, Lyon DG, Wells GAH: Spongiform encephalopathy in a captive puma (Felis concolor). Veterinary Record 1992, 7:431-434.

17. Peet RL, Curran JM: Spongiform encephalopathy in an imported cheetah (Acinonyx jubatus). Australian Veterinary Journal 1992, 7:171.

18. Baron T, Belli P, Madec JY, Moutou F, Vitaud C, Savey M: Spongiform encephalopathy in an imported cheetah in France. Vet Rec I997, I 4I(I I):270-27I.

19. Jeffrey M, Martin S, Thompson JR, Dingwall LWS, Begara-McGorum, Gonzalez L: Onset and distribution of tissue PrP accumulation in scrapie-affected Suffolk sheep as demonstrated by sequential necropsies and tonsillar biopsies. J Comp Path 200I, I 25:48-57.

20. Greenlee JJ, Hamir AN, West Greenlee MH: Abnormal prion accumulation associated with retinal pathology in experimentally inoculated scrapie-affected sheep. Vet Pathol 2006, 43:733-739.

21. Hortells P, Monzon M, Monleon E, Acin C, Vargas A, Bolea R, Lujan $L$, Badiola J]: Pathological findings in retina and visual pathways associated to natural Scrapie in sheep. Brain Research 2006, I 1 08: | 88-194.

22. Smith JD, Greenlee JJ, Hamir AN, West Greenlee MH: Retinal cell types are differentially affected in sheep with scrapie. J Comp Pathol 2008, I 38(I): I2-22.

23. Head MW, Northcott V, Rennison K, Ritchie D, McCardle L, Bunn TJR, McLennan NF, Ironside JW, Tullo AB, Bonshek RE: Prion protein accumulation in eyes of patients with sporadic and variant Creutzfeldt-Jakob Disease. Investigative Ophthalmology \& Visual Science 2003, 44:342-346.

24. Ligios C, Cancedda GM, Margalith I, Santucciu C, Madau L, Maestrale C, Basagni M, Saba M, Heikenwalder M: Intraepithelial and interstitial deposition of pathological prion protein in kidneys of scrapie-affected sheep. PLOS ONE 2007, 2(9):e859. I-8

25. Gregori L, Kovacs GG, Alexeeva I, Budka H, Rohwer RG: Excretion of transmissible spongiform encephalopathy infectivity in urine. Emerg Infect Dis 2008, I4(9): |406-|4|2.

26. Sisó S, Jeffrey M, Steele P, McGovern G, Martin S, Finlayson J, Chianini F, González L: Occurrence and cellular localization of PrPd in kidneys of scrapie-affected sheep in the absence of inflammation. J Pathol 2008, 2 I 5(2): I 26- I 34.

27. Terry LA, Marsh S, Ryder S], Hawkins SAC, Wells GAH, Spencer YI: Detection of disease-specific PrP in the distal ileum of cattle exposed orally to the agent of bovine spongiform encephalopathy. Veterinary Record 2003, I 52:387-392.
Publish with BioMed Central and every
scientist can read your work free of charge
"BioMed Central will be the most significant development for
disseminating the results of biomedical research in our lifetime. "
Sir Paul Nurse, Cancer Research UK
Your research papers will be:
• available free of charge to the entire biomedical community
• peer reviewed and published immediately upon acceptance
• cited in PubMed and archived on PubMed Central
• yours - you keep the copyright
Submit your manuscript here:
http://www.biomedcentral.com/info/publishing_adv.asp 